\title{
The Project Actuation of Course Teaching Reform Based on Blended Learning- - Taking Algorithm Design and Analysis for Example
}

\author{
Fang Ge \\ College of Computer engineering, Bengbu College, Bengbu 233030, China \\ gefang0616@sina.cn
}

Keywords: Algorithm Design and Analysis, Course Teaching, Project-oriented Teaching Pattern

\begin{abstract}
Algorithm design and analysis is the core courses of computer science and technology. This paper proposes improvement measure of the model of the hybrid teaching, project teaching, teacher's scientific research achievements as well as the ways of examination reform to solve the problem which introduce firstly existing in the process of the curriculum targets and teaching, which arm to improve the quality of teaching and provide environmental support for cultivating engineering applied talents.
\end{abstract}

\section{Introduction}

The precursor course of algorithm design and analysis is Object Oriented Program, Data Structure, Discrete Mathematics etc. On the base of precursor course, algorithm design and analysis mainly focus on the idea of algorithm, algorithm design, construction example, algorithm description and algorithm analysis ${ }^{[1]}$. The aim of this course is that improving students' ability to solve practical problems. That is to say, on basic understanding and mastery of the classic algorithm, design appropriate algorithm to solve practical problems, and then analysis the space complexity and time complexity of the algorithm. In the teaching process of the course, we find that there are many urgent problems to solve, such as, week mastery of knowledge of the precursor course ${ }^{[2]}$, besides, despise experiment and pay more attention to theory ${ }^{[3]}$. In addition, one-way teaching, less interaction ${ }^{[4]}$, and the final exam cannot reflect the students' ability of algorithm design and innovation in teacher's teaching process.

In the "engineering" education background, we explore a new teaching mode mixed blending learning, project-based teaching, teacher's scientific research achievement and the reform of examination in this paper. In this teaching model, we learn the advantages of various aspects to cultivate excellent students.

\section{The Necessity of Teaching Reform}

Undergraduate textbook of this course usually contain many content and involve a wide range. This lead to a problem that it is difficult for teacher to explain all classical algorithm clearly in relatively few hours, it is also difficult for student to master a lot of theoretical knowledge. At the same time, these textbook usually have little content to explain the practical application of the algorithm. In the experimental class, student main task is to verify the classical algorithm and few student have ability to improve and innovate algorithm.

\subsection{Weak Specialty of Basic Knowledge.}

In the practice of algorithm design and analysis, student need to write fluently programs to achieve the design algorithm, however, due to the weak speciality basic knowledge of programming course, it is lead to a not god situation that student not have enough ability for programming algorithm.

\subsection{Lay Emphasis on Theory and Less on Experimental Course.}

In the teaching process, teacher usually explain more classical algorithms such as greedy algorithms, divide-and-conquer algorithm, dynamic programming algorithm, search algorithm and etc. It is inevitable that teacher need a lot of time to explain these algorithm, that is to say, students have to understand these theory knowledge in a relatively short period of time, and it will lead to $\mathrm{s}$ 
situation that it is much more difficult for students with poor basic knowledge to understand, implement the corresponding algorithm or optimization algorithm.

\subsection{Unreasonable Assessment Methods.}

In general, the final examination of course is made up of the final examination which is worth $70 \%$ and evaluation of students' usual performance which is worth $30 \%$. In the final examination, teacher usually pay more emphasis on theoretical knowledge, and less on students' ability of design algorithm for practical problems, algorithm optimization or practical ability.

\section{Teaching Reform Measures}

Traditional classroom education is a kind of "teacher center" teaching model. Student are accustomed to "cramming" teaching model. With the accumulation of time, this teaching model will be limited to student's initative and innovation learning. With the development of global information technology, network curriculum model has gradually attracted the global attention of learners.

\subsection{Blended Learning.}

In December 2003, for is the first time, we import the implementation of Blended Learning ${ }^{[5-6]}$ in China, which expand a single traditional classroom teaching to the network classroom effectively combined the advantages of the traditional classroom teaching and network learning. On the one hand, the leading role of teacher's knowledge guidance and induction can be brought into an important auxiliary role, on the other hand, it can stimulate student's enthusiasm and creativity. Massive Open Online Course ${ }^{[7]}$ is a new way of learning which successfully transforms the subject of teaching from teacher to student, and finally achieves a better teaching effect. The comparison between the traditional classroom teaching and the flipped classroom teaching is shown in figure 1 .

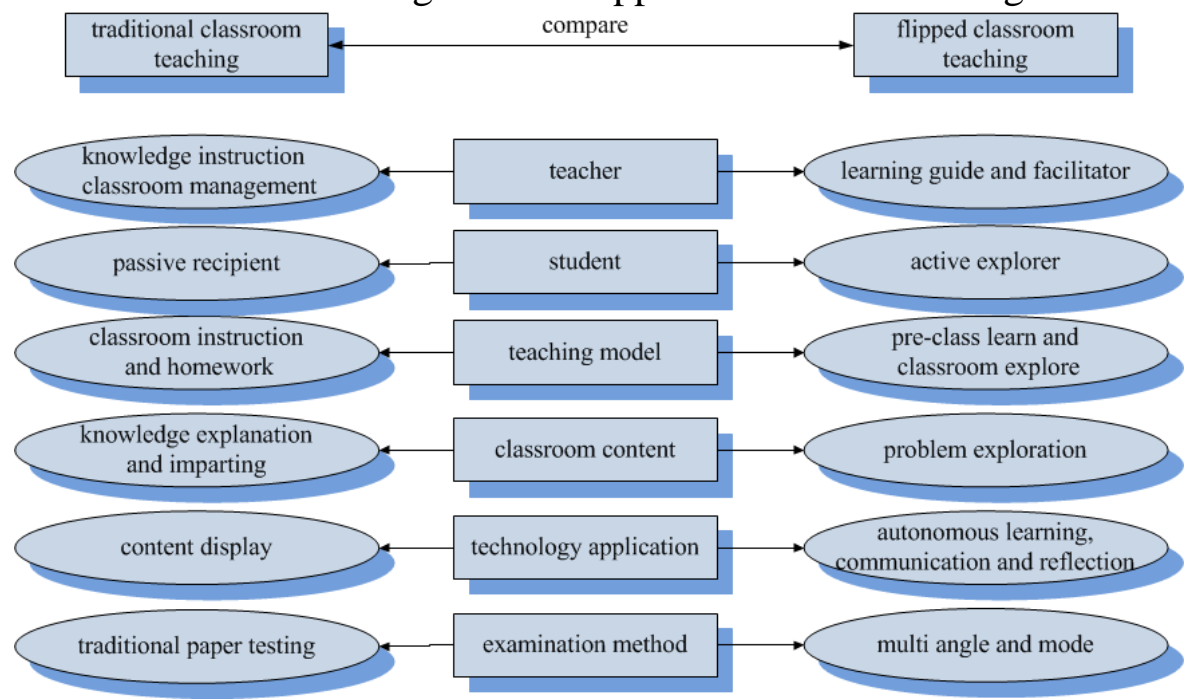

Fig. 1 The comparison between the traditional classroom teaching and the blended learning

Blended learning based on MOOC will make full use of the best quality and the most cutting-edge network resources including the research on knowledge of algorithm design and analysis, students can look for the related information according to their interest and learn knowledge autonomously. At present, the network quality resources of the curriculum has the following methods: Wang Hongzhi of Harbin Institute of Technology in net Ease cloud classroom, mainly on random algorithms, approximation algorithms, large data algorithms, computational geometry, combinatorial optimization articles, etc. In addition, Deng Zhilong of Northwestern polytechnic AL University and the development of curriculum 30 videos by Chinese Academy of Sciences, etc.

\subsection{Project Development.}

The algorithm design and analysis course is closely linked with the development of engineering projects. In the process of development, we need to analyze the problem and process specific problems with the algorithm. Therefore, in the course of the teaching, the development of specific project should be carried out to deepen the understanding of the theoretical knowledge and practical ability of students. The relationship between the problem solving process and the required courses in 
the project development process is shown in figure 2. From figure 2, we can conclude that the algorithm design is the core of project development.

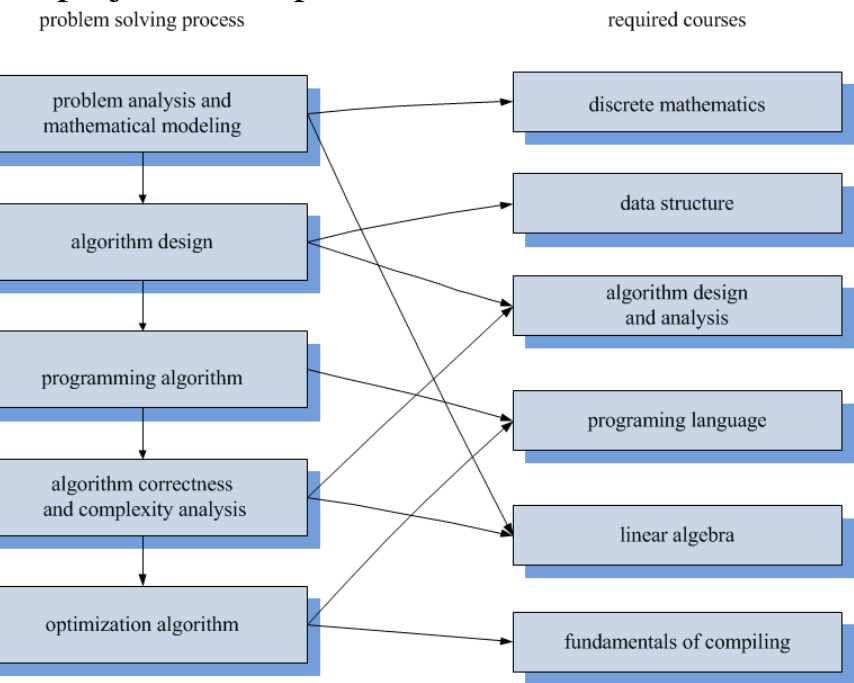

Fig.2 Problem solving process and required courses in project development

\subsection{Introducing Research Achievement to Teaching.}

For the algorithm design and analysis course, college teachers should integrate the idea of "scientific research to promote teaching" into the daily teaching. Instructor of the course should introduce the study of the latest research results and the classical algorithm in the field into the teaching and stimulate students' interest in the field of algorithm research.

\subsection{Examination Method.}

This course assessment is combined with final examination and student's usual performance, proportion is usually 7:3. In general, student's usual performance mainly include attendance in class, the completion of homework and the integrity of the experimental report. It is difficult to examine the idea of the students to optimize the algorithm and innovative algorithms. Therefore, we adjust some scores as shown in table 1.

Table 1 the proportion of student's usual performance

\begin{tabular}{cc}
\hline before the Reformation(30\%) & before the Reformation(30\%) \\
\hline class attendance(15\%) & class attendance(5\%) \\
& Experiment completion (5\%) \\
Experimental innovation (5\%) \\
Experimental report integrity (5\%) \\
Experimental report integrity (15\%) & Algorithm design integrity of the project (5\%) \\
& Algorithm optimization in project development (5\%) \\
\hline
\end{tabular}

\section{Teaching Model Design}

Combined with the measures of curriculum reform shown in chapter three, the curriculum reform program of algorithm design and analysis will be shown in figure 3.

(1) There are so many high-quality MOOC courses in the network, but also a lot of content, for example, the basic knowledge of algorithm, algorithm explanation, algorithm analysis and implementation, the specific application of the algorithm, algorithm optimization. Students can find relevant resources in the MOOC course and preview the contents of the class in advance.

(2) Teacher introduce specific project on the basis of student's understanding of the contents of this chapter, then, encourage student to find some key problems of the project which need to be resolved. In order to solve these problems, teacher analysis the problem, extract the data and put forward the mathematical model. Finally, try to find the classical algorithm solving these problem and then introduce the algorithm.

(3) According to the specific problems, teacher analysis the classical algorithm. Student are required to realize the algorithm by programming languages which have been mastered, then analysis the time complexity and space complexity of the algorithm for specific data input. 
(4) Infer other things from one fact. Dispose of solving this problem, let student think which kind of problem can be solved by this algorithm proposed above in daily life. This process training can improve student's awareness and ability to apply theory to practice.

(5) On the basis of understanding and mastering of the classical algorithm, encourage student to try to find out whether the algorithm can be optimized or not. Teachers should introduce the optimization algorithms and applications to students using their scientific research, so as to stimulate the student's interest in improvement of the algorithm.

(6) After the end of the course, we reform the traditional form of assessment, that is to say, we will regard algorithm optimization and experimental innovation as an important assessment factor.

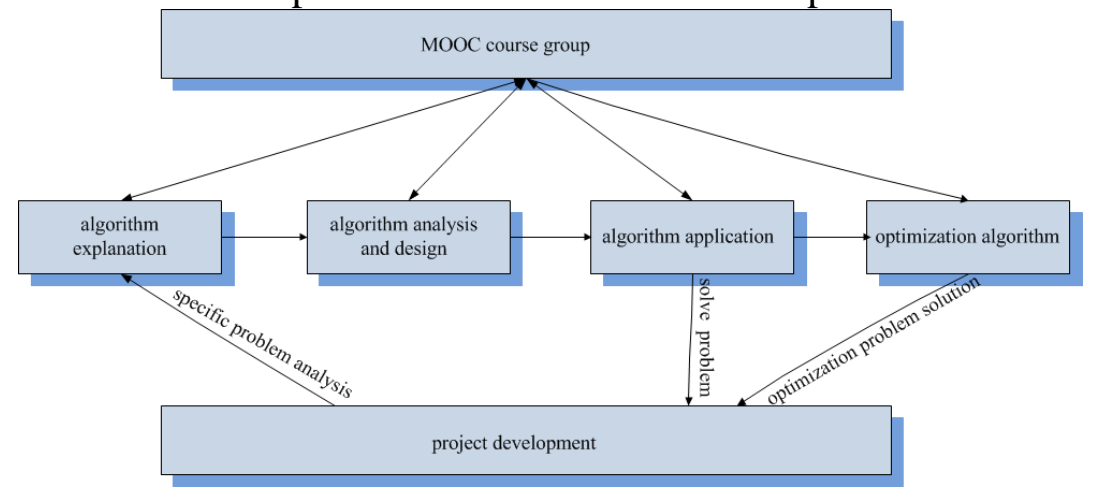

Fig.3 Course reform scheme

\section{Conclusion}

Under the engineering education background, this paper analysis and summary the existing problem of algorithm design and analysis course and propose curriculum reform which combine project development, teacher's research and curriculum assessment on the basis of Blended Learning. The purpose of this reform is to improve the quality of teaching and to provide technical support for cultivating student's abilities of practical application.

\section{References}

[1]. Wang Qiuf-en, Lu Cong-ying, Zhou Chun-guang. Algorithm Design and Analysis [M].Tsinghua Press, 2011

[2]. Feng Gui-ling, Wu Jing-song. Discussion on the Course Features and Teaching Method of Design and Analysis of Algorithm [J]. Modem Computer, 2012(20):48-49.

[3]. Chen Bao-ping. Reformation, Innovation and Practice of Software Talents Training [J].Modem Computer, 2012(12):37-39.

[4]. LI Jian-zhong. Exploration of the Teaching Method in Design and Analysis of Algorithms [J]. Modern Computer, 2014(14):24-26

[5]. Lalima Dangwal, Kiran Lata. Blended Learning: An Innovative Approach. [J].Universal Journal of Educational Research, 2017, 5.

[6]. Lam J, Lau N, Shim C, et al. Design and development process for blended learning courses [J]. International Journal of Innovation \& Learning, 2013, 13(3):322-338.

[7]. The New York Times. The Year of the MOOC [EB/OL].2012-12-05. 